\title{
DEM Simulation and Analysis of Seeds Supply by the Vibrating Seed Box of Magnetic Cylinder Seeder
}

\author{
Xiuping Shao, Jianping Hu, Yingsa Huang, and Fa Liu \\ Key Laboratory of Modern Agricultural Equipment and Technology, Ministry of \\ Education\&Jiangsu Province, Jiangsu University, Zhenjiang 212013, China \\ shaoxiuping 858@gmail. com
}

\begin{abstract}
Regarding the vibrating seeds box of magnetic cylinder seeder as the research subject and making simulation and analysis for the motion law of seeds which supplied by seed box base on DEM (Discrete Element Method). Researching the mechanism of the seed supply and analyzing the condition of seed supply by the vibration of seed box, when the frequency change from $10 \mathrm{~Hz}$ to $50 \mathrm{~Hz}$ and horizontal and vertical amplitude of the seed box are $0.5 \mathrm{~mm}$. The results shows that the vibrating frequency has greater influence on the seed supply; seeds can't be supplied when the vibrating frequency less than $10 \mathrm{~Hz}$; seed can be supplied best and seeds thickness nearly the cylinder wall is highest when the vibrating frequency equal to $40 \mathrm{~Hz}$.
\end{abstract}

Keywords: Seed Box, Discrete Element Method, Seed Supply, Vibration, Frequency.

\section{Introduction}

Magnetic cylinder seeder can realize the seeding of vegetables, flowers and other small seeds [1]. Its important working assembly is the vibrating seed box which relied on vibrator to supply seeds continuously and stably to the cylinder wall, so the vibration parameters directly affect the property of seeder. There are complex interrelationship collision and friction in the motion of the seeds, which kinematics and dynamics relationship is quite complex, that the traditional continuum mechanics can't analyze the actual movement of seeds [2] [3]. This paper using discrete element method, studying the seed supply situation under the condition of seed box vibration, which provided theoretical basis for the further research of magnetic cylinder seeder.

\section{Structure and Working Principle of Magnetic Cylinder Seeder}

The structure of magnetic cylinder seeder is shown in fig.1, including cylinder, drive shaft, permanent magnet, seed box, vibration exciter etc.

Powder coated seeds are placed in half-open vibrating seed box, the open side nearly close to the cylinder wall to prevent seeds falling down; Seeder wheel drives by shaft and makes one way rotating, permanent magnet mounts on the rotating shaft, the magnetic head mounts on the channel of the cylinder and rotates with the cylinder. When the magnetic head turns to the region of seed-filling, the magnetic head adsorb 


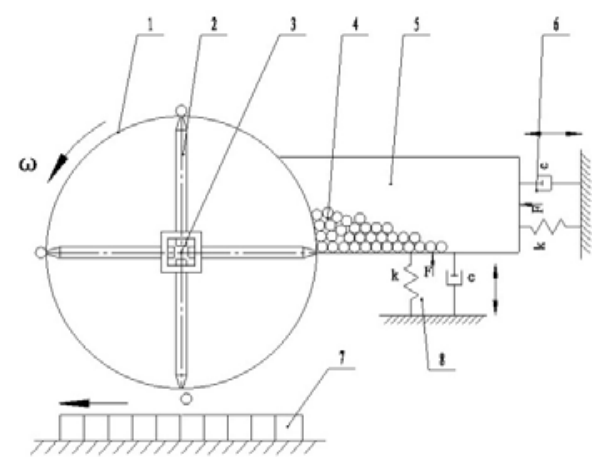

1.Cylinder 2.Permanent magnet 3.Drive shaft 4.Seed 5.seed box 6. Longitudinal vibration exciter 7.Seed plate 8.Transverse vibration exciter

Fig. 1. The structure of precision magnetic cylinder seeder

one seed and continue rotates with cylinder, when it turn to the downside of cylinder roller, the seed falls down then one time metering completely.

\section{Contact Force Model and Parameter Definition}

Contact force model is the core of DEM, the simplify model is always used for calculation during DEM simulation due to much more complex structure particles. The linear viscoelastic contact model has been widely used in the research of the agricultural machinery [4 6], so adopting the linear viscoelastic contact model as the contact force model of seed-seed and seed-seeder elements.

The normal force of liner viscoelastic model [7]:

$$
F_{n}=-k_{n} \delta_{n}-c_{n} \theta_{n} .
$$

$F_{n}:$ The normal force between two contact particles;

$k_{n}$ : The normal contact stiffness coefficient, $k_{n}=\frac{k_{1} k_{2}}{k_{1}+k_{2}}$;

$k_{1}, k_{2}$ : The contact stiffness coefficients of two contact particles;

$\delta_{n}$ : The normal overlap of two contact particles;

$C_{n}$ : The normal viscous damping coefficients, $C_{n}=\frac{C_{1} C_{2}}{C_{1}+C_{2}}$;

$C_{1}, C_{2}$ : The normal viscous damping coefficient for two contact particles;

$\theta_{n}$ : The normal contact relative velocity.

Tangential contact force is:

$$
F_{s}(t)=F_{s}(t-\Delta t)-K_{s} \theta_{s} \Delta t-c_{s} \theta_{s} .
$$


$F_{S}(t):$ The tangential force between two contact particles at time t;

$\Delta t:$ The time step;

$K_{s}$ : The tangential contact stiffness coefficient.

All the parameter needed in the simulation are got from experiment, the details are shown as table 1 .

Table 1. Parameter used in DEM analysis

\begin{tabular}{lc}
\hline Seed type & Coating rapeseed (iron 20\%) \\
\hline Particle diameter/mm & 3.5 \\
Poisson's ratio of particle & 0.3 \\
Shear modulus of particle/Pa & $4.65 \times 10^{8}$ \\
Particle density/Kg $\cdot \mathrm{qm}^{3}$ & $2.1 \times 10^{3}$ \\
Coefficient of restitution in seed-seed & 0.2 \\
Static friction coefficient in seed-seed & 0.4 \\
Rolling friction coefficient in seed-seed & 0.06 \\
Coefficient of restitution in seed-seeder elements & 0.4 \\
Static friction coefficient in seed-seeder elements & 0.11 \\
Rolling friction coefficient in seed-seeder elements & 0.02 \\
\hline
\end{tabular}

\section{Simulation Results}

According to the actual experiment, when the seed box amplitude was $0.5 \mathrm{~mm}$, metering requirement can be satisfied. During simulation experiment, $0.5 \mathrm{~mm}$ was selected for the horizontal and vertical amplitude. And simulated the seed supply situation and the movement law of the seeds under the vibration frequency was $10 \sim 50 \mathrm{~Hz}$.

During the Simulation, cylinder diameter was $100 \mathrm{~mm}$, the rotation speed was 20r/min, the size of the seed box was $170 \times 60 \times 50 \mathrm{~mm}$ (length $\mathrm{x}$ width $\mathrm{x}$ height). 1500 seeds were generated with a normal distribution, which average diameter equal to $3.5 \mathrm{~mm}$ and the variance was 0.05 . Once the filling completed, the seed box started to make a simple harmonic oscillation with the vertical and horizontal direction. There can be clearly shows that influence of frequency for motion of seed supply according to the simulation result. The duration time of numerical simulation was 3 seconds.

\subsection{The Motion Law of Seeds}

During the vibration process, seeds always kept the moving condition with friction and collision. When the vibration frequency was low, the seeds moved slowly to the cylinder wall direction, and no longer moved forward when seeds moved to the certain condition. Meanwhile the seeds can only peristalsis with the seed box and unable to be supplied for the seeder, as shown in Fig.2; When the vibration frequency was high, the impetus force that took seeds moved towards to the roller was bigger than 
the friction force, so seeds moved to the roller direction at a certain speed, and formed a accumulative in the roller wall edge, until seeds movement were steady. At this moment, the seeds would be supplied to seeder stably, as shown in Fig.3.

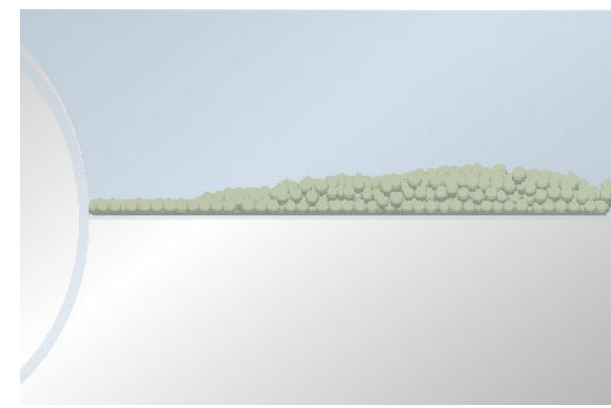

Fig. 2. Seed supply diagram $(\mathrm{f}=10 \mathrm{~Hz})$

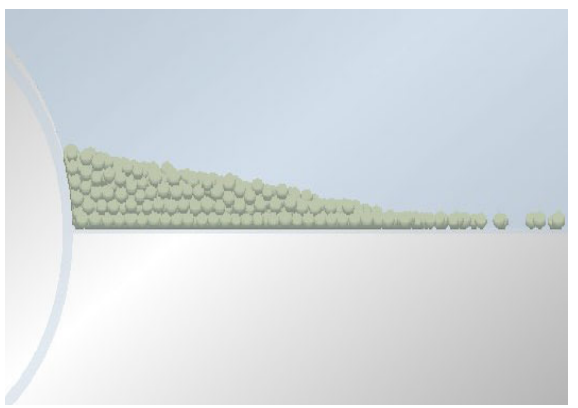

Fig. 3. Seed supply diagram $(\mathrm{f}=40 \mathrm{~Hz})$

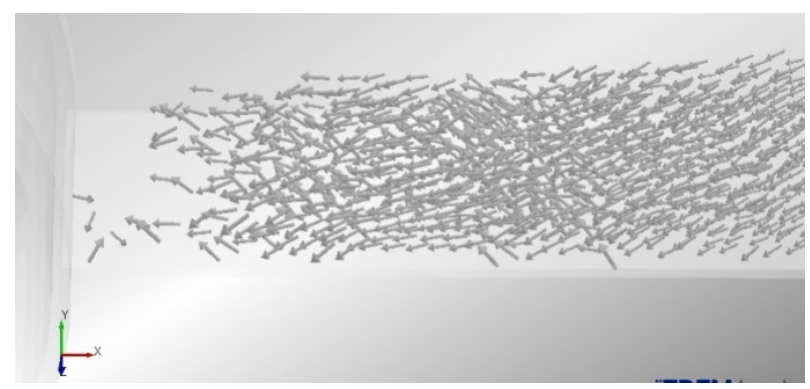

(a) $\quad \mathrm{t}=0.3 \mathrm{~s}$

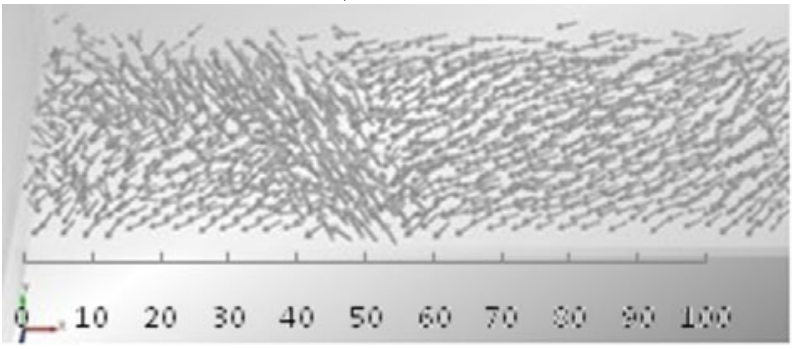

(b) $\quad \mathrm{t}=0.5 \mathrm{~s}$

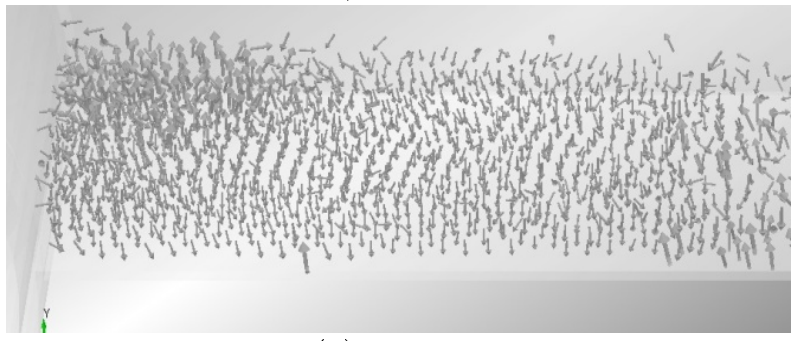

$$
\text { (c) } \mathrm{t}=1.5 \mathrm{~s}
$$

Fig. 4. Instantaneous velocity vector of seeds movement $(f=50 \mathrm{HZ})$ 
In order to understood the motion of seeds supply situation deeply, this paper simulated the vibration process of seed box when frequency was $50 \mathrm{~Hz}$. Fig. 4 shown the instantaneous velocity vector chart of the seeds movement when the vibration frequency was $50 \mathrm{~Hz}$. It can be seen clearly from the figure that the seeds were influenced by both 1 horizontal and vertical direction amplitude, and moved towards to the cylinder and upward directions.

It can be seen from fig.4(a) that after the seed box vibrated $0.3 \mathrm{~s}$, the majority seeds moved towards the roller direction by a certain speed; it can be seen from Fig.4(b) that after the seed box vibrated $0.5 \mathrm{~s}$, partial seeds contacted and collided with the roller wall, and had a tendency to rebound, enabled these seeds collided once more with the seeds which were moving towards the cylinder direction, there formed a disordered area that the spacing from the roller was 50mm; fig.4(c) showed that, after seed box vibrated $1.5 \mathrm{~s}$, the seeds movement basically tends to be stable, with merely creeping motion along with the vibration of the seed box, now seeds in seed box achieved a steady situation for seeds supply.

\subsection{Frequency Effect on Seed Supply Situation}

Seeds moved towards to the and finally form a certain altitude along the edge of cylinder wall. In this paper, the accumulation height on the cylinder wall edge $\mathrm{H}$ was used as the indicator quality of seed supply, as shown in Fig.5.

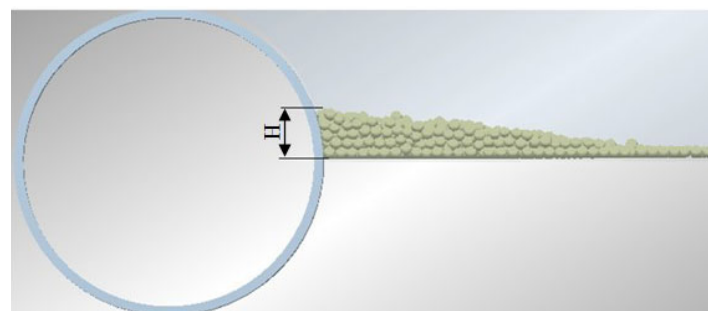

Fig. 5. Seeds accumulation height diagram

The vibration frequency of the seed box was respectively set at $10 \mathrm{~Hz}, 20 \mathrm{~Hz}, 30 \mathrm{~Hz}$, $40 \mathrm{~Hz}, 50 \mathrm{~Hz}$, simulated the movement process of the seeds along the cylinder wall edge. The simulation result was shown in Fig.6. It can be seen from the figure that the vibration frequency influenced the seeds movement obviously. When the vibration frequency of the seed box was set at $10 \mathrm{~Hz}$, the seeds accumulation height was nearly 0 , therefore the seed supply were defeated; with the increase of the vibration frequency the accumulation height along the roller wall edge also increased; when the vibration frequency of the seed box was $40 \mathrm{~Hz}$, seeds accumulation height was largest, at this condition seed supply got the best state.

For particular described the condition of seed supply by the vibration of seed box, set a small selection that length $\times$ high $\times$ weight was $10 \mathrm{~mm} \times 15 \mathrm{~mm} \times 30 \mathrm{~mm}$ along the edge of cylinder wall, as shown in fig. 7 .

Analyzed the quantity of seeds of this selection in different moment when the vibration frequency of seed box was $10 \mathrm{~Hz}, 20 \mathrm{~Hz}, 30 \mathrm{~Hz}, 40 \mathrm{~Hz}$. 


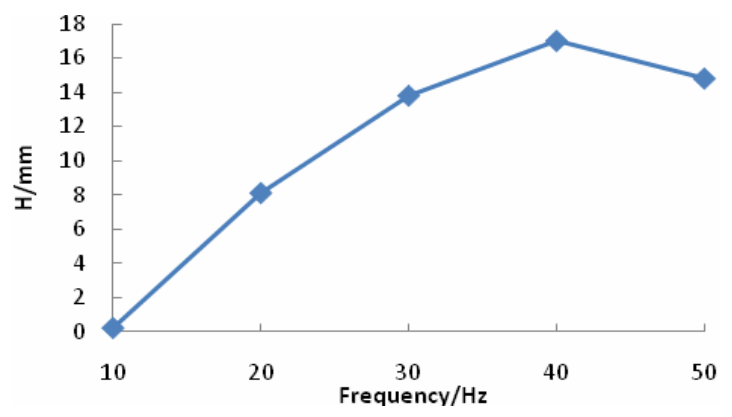

Fig. 6. Seeds accumulation heights under different frequencies

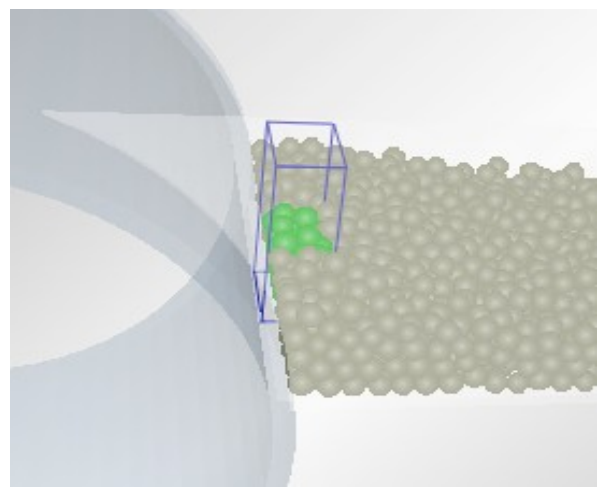

Fig. 7. Small selection along the edge of cylinder wall

As shown in fig.8, seeds entered the small selection along the edge of cylinder wall after seed box vibrating for a period of time; after some time the quantity of seeds in the selection reached a plateau, and the time turned short with the vibration frequency increased; after the quantity of seeds reach a plateau, the quantity of seeds has a greatly difference between different frequencies; the larger of the frequency, the more the seeds in the selection, and the better of the condition of seed supply.

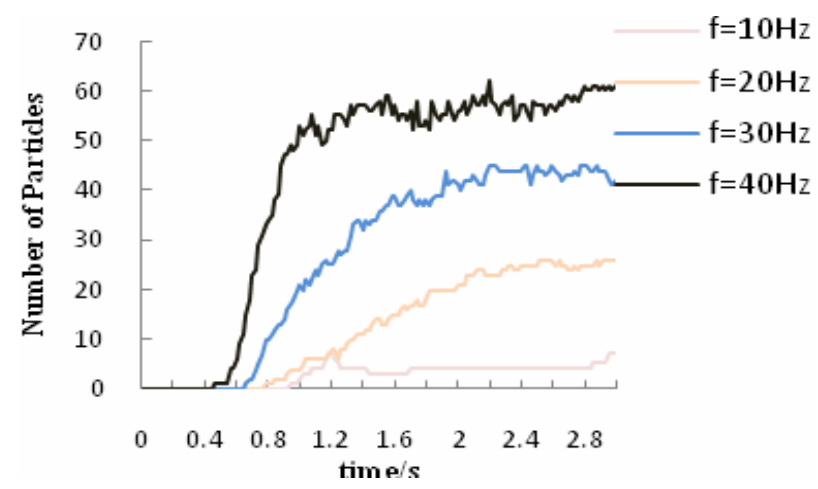

Fig. 8. Seeds total number in small selection under different times 


\section{Conclusion}

Made the vibration seed box of precision magnetic cylinder seeder as research object in this paper, the seed motion law and supply with different frequencies base on DEM were numerical analysis, such conclusions were derived:

1. Using DEM can easily and accurately simulate seeds motion law in the vibration seed box.

2. At the beginning of the vibration, seeds moved toward to cylinder with a certain speed; when seeds contacted with the cylinder, part of them rebounded and collided with the behind seeds which moved to the cylinder wall, then raised a disturbance area within $50 \mathrm{~mm}$ leave from the cylinder wall; seeds campaign achieved a smooth situation again and only did upward or downward reciprocating movement, then the seed provided in the seed box became to stabilized.

3. Vibration frequency has great influence on seed accumulate height nearly the cylinder roller edge. Seed accumulate height nearly the cylinder roller edge go up with the vibration frequency increased. The seed box can't supply seed when vibration frequency was lower than $10 \mathrm{~Hz}$ and the best supply seed with the vibration frequency equal to $40 \mathrm{~Hz}$.

4. The seeds reached the edge of the cylinder roller wall after a period of vibration; the time required for achieving stability of the seed near the cylinder wall was proportional to the vibration frequency, moreover the more the seeds due to higher frequency, the better for the seed supply situation.

\section{Acknowledgements}

This work was financially supported by eleventh five-year-plan national scientific \& technological supporting project (2006BAD11A10) and agricultural mechanization in three agriculture projects, Jiangsu province (NJ2009-41).

\section{References}

1. Li, Y., Zhao, Z., Chen, J., et al.: Discrete Element Method Simulation of Seeds Motion in Vibrated Bed of Precision Vacuum Seeder. Transaction of the Chinese Society for Agricultural Machinery 40(3), 56-60 (2009)

2. Sun, Y., Ma, C., Niu, X., et al.: Discrete Element Analysis and Animation of Soybean Precision Seeding Process Based on CAD Boundary Model. Transaction of the Chinese Society for Agricultural Machinery 37(11), 45-48 (2006)

3. Yu, J., Shen, Y., Niu, X., et al.: DEM Simulation and Analysis of the Clearing Process in Precision Metering Device with Combination Inner-cell. Transactions of the CSAE 24(5), 105-109 (2008)

4. Williams, J.R., Rege, N.: The development of circulation cell structures in granular materials undergoing compression. J. Powder Technology 90, 187-194 (1997)

5. Dziugys, A., Peters, B.: A new approach to detect the contact of two dimensional elliptical particles. Int. J. Numer. Anal. Meth. Geomech. 25, 1487-1500 (2001) 
6. Liu, A., Liu, S., Pan, Z.: Numerical Simulation of Movement of Solid Particles in a Vibrating Feeder. Journal of the Graduate School of the Chinese Academy of Sciences 19(1), 35$42(2002)$

7. Cundall, P.A., Strack, O.D.L.: A Discrete Numerical Model for Granular Assemblies. Geotechnique 29, 47-65 (1979)

8. Zhao, Y., Zhang, M., Xu, P., et al.: Discrete element simulation of the microscopic mechanical structure in sandpile. Acta Physica Sinica 58(3), 1819-1825 (2009)

9. Zhao, Y., Zhang, M., Zheng, J.: Discrete element simulation of the segregation in Brazil nut problem. Acta Physica Sinica 58(3), 1812-1818 (2009) 